\title{
Assessment and Mapping of Groundwater Vulnerability Using SAR Concentrations and GIS: A Case Study in Al-Mafraq, Jordan
}

\author{
Majed Ibrahim ${ }^{1}$, Barbara Koch ${ }^{2}$ \\ ${ }^{1}$ Geographic Information System and Remote Sensing Department, Al al-Bayt University, Mafraq, Jordan \\ ${ }^{2}$ Remote Sensing and Landscape Department (Felis), Freiburg University, Freiburg, Germany \\ Email: *majm_2faris@yahoo.com, franz.barbara.koch@t-online.de
}

Received 25 April 2015; accepted 24 May 2015; published 27 May 2015

Copyright (C) 2015 by authors and Scientific Research Publishing Inc.

This work is licensed under the Creative Commons Attribution International License (CC BY). http://creativecommons.org/licenses/by/4.0/

(c) (i) Open Access

\begin{abstract}
Groundwater is the main source of water supply in Jordan. Due to lower precipitation rates in recent years, the surface water is increasingly limited. Research on groundwater vulnerability helps protect this main source of water supply and assists in the development of plans to confront the deterioration and contamination of aquifers from wastewater and agricultural activities in order to protect groundwater for future generations. The important factors to determine groundwater vulnerability are environmental conditions; hence the spatial conditions in arid to semi-arid areas must be taken into account when applying different models. The aquifer vulnerability has been assessed in Jordan by using the DRASTIC method; remote sensing and Geographic Information System (GIS) data were used to derive and process data. The DRASTIC index was used with seven parameters to describe physical characteristics of the aquifers. It is concluded that about $34 \%$ of the area was considered to be of moderate vulnerability, but the share increased to $60 \%$ after modifying the index. While high vulnerability was at $25 \%$ of the total area, it decreased to $6.3 \%$ with the modified index; therefore, urgent pollution prevention measures should be taken for every kind of relevant activity within the whole basin.
\end{abstract}

\section{Keywords}

Land Use, Groundwater, DRASTIC Index, GIS, SAR

\section{Introduction}

Like many other countries in the world, Jordan faces serious problems related to water shortages, which nega${ }^{*}$ Corresponding author.

How to cite this paper: Ibrahim, M. and Koch, B. (2015) Assessment and Mapping of Groundwater Vulnerability Using SAR Concentrations and GIS: A Case Study in Al-Mafraq, Jordan. Journal of Water Resource and Protection, 7, 588-596. 
tively affect its entire development. Worldwide, Jordan is considered to be one of the four poorest countries in terms of water resources. Water use in the country has already exceeded renewable freshwater resources by more than 20\%, and after 2005, the Jordanian Ministry of Water started to think about using full freshwater; in the same time, it has not developed the means and search capabilities to find new water resources in the country. Increasing water demand on the existing resources combined with declining rainfall and increasing temperatures as a result of climatic changes causes the most serious problems.

Groundwater vulnerability studies are expected to draw the attention of land-use planners and decision-makers to the effects to groundwater of human activities on the soil, especially for the identification of harmful contaminants in aquifers [1]. This should give them an information basis to take action in order to improve the situation. There are several approaches for developing groundwater vulnerability assessment maps, such as DRASTIC [2], GOD [3], and SINTACS [4] — which have been developed for limestone aquifer areas, as well as the COP [5], EPIK [6], and PI [7] methods which have specifically been developed to assess the vulnerability in karst areas.

DRASTIC is an overlay and indexing method which is widely used to assess groundwater vulnerability to a wide range of potential contaminants. [8] stated that DRASTIC has been used throughout the world with exceptional frequency, having been developed in the US Environment Protection Agency (USEPA) by [2]-[9]. One of the major advantages of the DRASTIC model is the implementation of assessment by using a large number of input data layers [10], which is believed to limit the impacts of errors or uncertainties of the individual parameters on the final output [11]. The DRASTIC index is considered to be one of the comparative models, and it is also flexible in its application where all available datasets are almost reliable. The characteristics of the model are boundless, depending on aquifer as well as topography properties, and the hydrological and lithological environments in the study area.

Different environmental parameters interfere when anticipating the amount and location of impurities that may affect the aquifers, especially if used for the water being extracted from aquifers for irrigation and other uses that have an impact on the environment. Groundwater settings, hydrological and hydrogeological conditions, land-use parameters, environmental issues, soil parameters, and other elements, which may vary from one aquifer and from one area to another, are used to determine the vulnerability of groundwater [12]. Several studies have used the DRASTIC model within a GIS environment although few attempts have been made to apply this methodology in arid and semi-arid environments [13].

The objective of the present study was to assess the Sodium Absorption Ratio (SAR) in wells as an index for water quality within groundwater vulnerability zones. Based on these measurements, the suitability of different uses of the water (i.e. domestic, irrigation, and drinking purposes) was evaluated. The analysis was conducted by using the modified DRASTIC index in combination with GIS techniques and remote sensing, resulting in a significant relationship between SAR values of irrigation water and the extent to which sodium is absorbed by the soils [14]. Continued use of water with a high SAR value leads to a breakdown in the physical structure of the soil, caused by excessive amounts of sodium being absorbed by the soil. This study aims to highlight the areas sensitive to pollution and to show the risk of the water quality deterioration to predict the impact expected if the problem continues without wells irrigation monitoring and land use management.

\section{Study Area}

The study area is located in the north-eastern part of the Yarmouk basin in Jordan Figure 1. It has a semi-arid climate of the Mediterranean region with a limited amount of rainfall and high temperatures. Mean annual rainfall and temperatures are $350 \mathrm{~mm}$ and $18^{\circ} \mathrm{C}$, respectively, as measured at the Irbid station (north Jordan).

In general, the groundwater aquifers of Jordan can be divided into three main hydraulic complexes [15]: the Deep Sandstone Aquifer Complex, the Upper Cretaceous Aquifer Complex, and the Shallow Aquifer Complex. Although this study is concentrated on the Upper Cretaceous and Shallow Aquifers, it is important to mention the significant role of the Deep Sandstone Aquifer Complex which is located in the adjacent highlands. It may contribute to the recharge of the Upper Cretaceous and Shallow Aquifers by upward leakage, as suggested by [16], or through lateral groundwater flow directed from the mountain foothills towards the Jordan River [17]. Adopted selection of this area on multiple land use in that area on a regular basis and the subsequent problems the problems, and the NE of Jordan aquifer that located study is considered to be of higher quality water for other aquifers. 

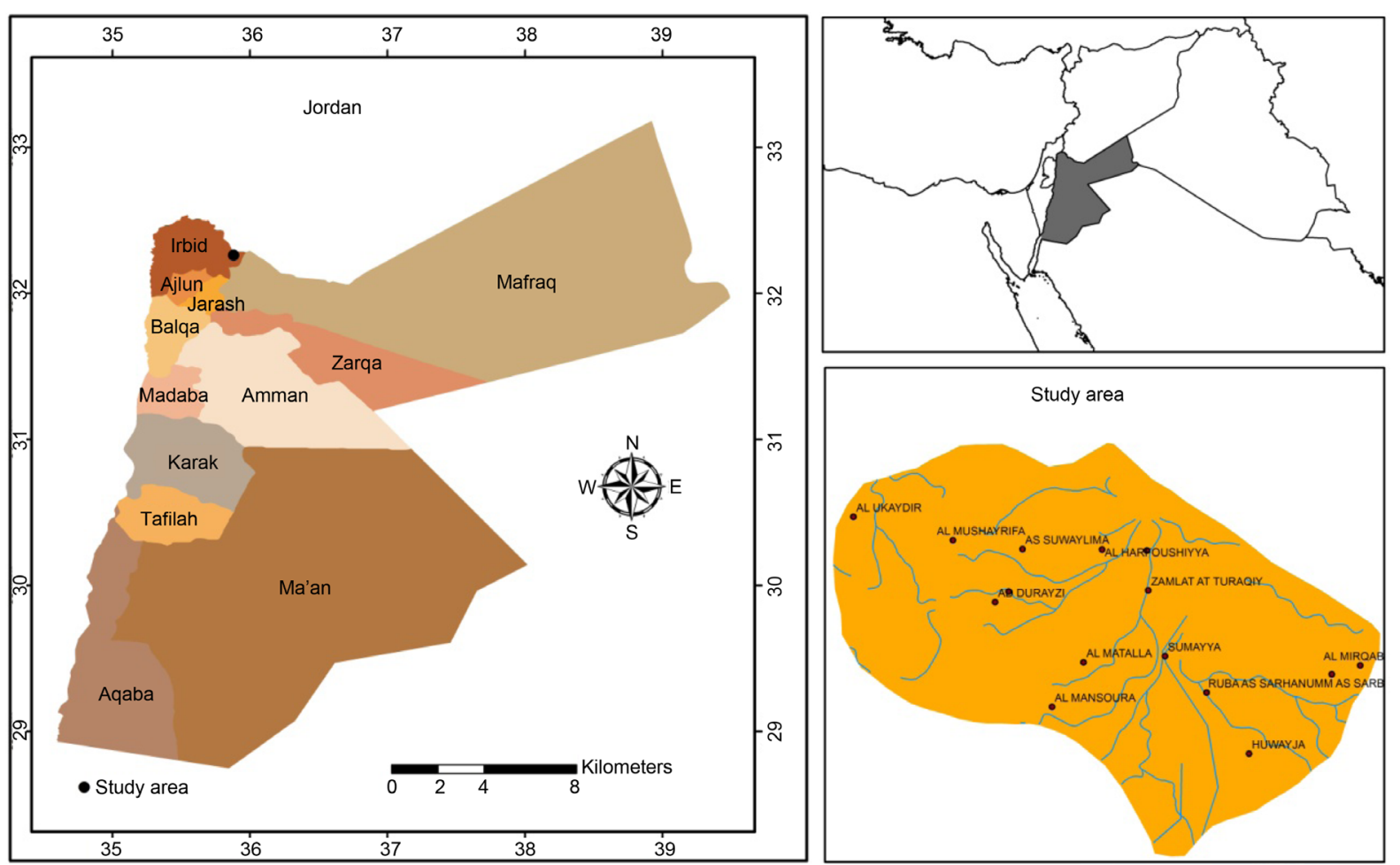

Figure 1. Study area.

\section{Methodology}

\subsection{DRASTIC Index}

Based on the particular conditions in semi-arid areas such as aridity, strong fluctuations in precipitation amounts and distribution, physical properties, etc., a new vulnerability index needs to be developed which is mainly based on the gradient of the depth to groundwater, the ease of the pollutants to migrate to the groundwater, on soil type, net recharge equation, and land use.

The rating of these variables depends on their importance for water pollution (Table 1). The DRASTIC index given in the equation above is considered to be an indicator for the pollution potential [8]. The general equation of the DRASTIC index was defined by [2] and was used in this research without the hydraulic conductivity parameter because it lacks suitable data. The modified DRASTIC index-as proposed by [18] for the recharge ratings and weightings by [19] for the land-use ratings and weightings, and by [20]. The remaining parameter weights and ratings is supposed to be suitable for different aquifer rock types, particularly for arid and semi-arid areas.

The general equation for the (modified) DRASTIC index and is Equation (1):

$$
\text { DRASTIC index }=\mathrm{DrDw}+\mathrm{RrRw}+\mathrm{ArAw}+\mathrm{SrSw}+\mathrm{TrTw}+\mathrm{IrIw}+\mathrm{Cr} \times \mathrm{Cw}
$$

The main factors in the modified DRASTIC index are:

Depth to groundwater (D): The depth to groundwater in the study area was about $200 \mathrm{~m}$ in all wells [21] [22]. The depth index was obtained from the depth rank and the depth weight; $\mathrm{Dr} \times \mathrm{Dw}=5$ (Table 1 ). This value was estimated based on the weighting system [2] [20] (Table 2).

Net recharge (R): Recharge to the groundwater as a portion of rainfall amounts. This depends on rainfall data, soil permeability and the topographic setting (Equation (2)). In order to calculate the recharge value (RrRw), a digital elevation model (DEM) of the study area was generated at $10 \mathrm{~m}$, and the net recharge map was sub- divided into two classes.

$$
\text { Recharge Value }=\text { Slope } \%+\text { Rainfall }+ \text { Soil Permeability }
$$

Aquifer media (A): This hydrogeological factor describes the ability of pollutants to move within the aquifer 
Table 1. The rate and weight for the parameters of the DRASTIC Index [2] [15] [17].

\begin{tabular}{|c|c|c|c|c|}
\hline Parameters & Range & Rate (Xr) & Weight (Xw) & Total Weight (XrXw) \\
\hline Depth to groundwater (m) & Less than $200 \mathrm{~m}$ & 5 & 1 & 5 \\
\hline \multirow[t]{2}{*}{ Recharge (Range) } & $4-6$ & 3 & 2 & 6 \\
\hline & $7-9$ & 5 & & 10 \\
\hline \multirow{2}{*}{ Aquifer media (Material) } & \multirow{2}{*}{$\begin{array}{l}\text { Limestone } \\
\text { Basalt }\end{array}$} & 6 & \multirow{2}{*}{3} & 18 \\
\hline & & 9 & & 27 \\
\hline \multirow{2}{*}{ Soil media (Type) } & \multirow{2}{*}{$\begin{array}{l}\text { Silt loam } \\
\text { Clay loam }\end{array}$} & 3 & & 15 \\
\hline & & 5 & 5 & 25 \\
\hline \multirow{4}{*}{ Topography-slope (\%) } & $0-2$ & 3 & 3 & 9 \\
\hline & $2-6$ & 5 & & 15 \\
\hline & $6-12$ & 9 & & 27 \\
\hline & $12-18$ & 10 & & 30 \\
\hline \multirow{2}{*}{ Impact of the vadose zone } & Limestone & 6 & & 24 \\
\hline & Basalt & 9 & 4 & 36 \\
\hline Conductivity range $\mu \mathrm{s} / \mathrm{cm}$ & No data & - & & - \\
\hline \multirow{3}{*}{ Land use } & \multirow{3}{*}{$\begin{array}{c}\text { Urban } \\
\text { Irrigated field and crops } \\
\text { Uncultivated }\end{array}$} & 8 & 5 & 40 \\
\hline & & 8 & & 40 \\
\hline & & 5 & & 25 \\
\hline
\end{tabular}

Table 2. Generation of recharge factor [18] [22] [23].

\begin{tabular}{cccccccc|}
\hline \multicolumn{1}{r}{ Slope } & \multicolumn{2}{c}{ Rainfall } & \multicolumn{2}{c}{ Permeability } & \multicolumn{2}{c}{ Net Recharge } \\
\hline Slope (\%) & Factor & Rain & Factor & Type of soil & Factor & Range & Rating \\
\hline $\mathbf{2}>$ & 4 & $<600$ & 4 & Sandy loam & 4 & $3-6$ & 1 \\
$\mathbf{2}-\mathbf{1 0}$ & 3 & $600-700$ & 3 & Silty clay loam & 2 & $6-7$ & 3 \\
$\mathbf{1 0}-\mathbf{3 2}$ & 2 & $700-860$ & 2 & - & - & - & - \\
$\mathbf{3 3}<$ & 1 & $>860$ & 1 & - & - & - & - \\
\hline
\end{tabular}

according to its type. Based on the geological description of the study area, the aquifer media was classified as fractured basalt and limestone [2] [20]. The net aquifer media was sub-divided into (2).

Soil media (S): This factor describes the ability of pollutants to move within the soil down to the groundwater according to the size distribution of the soil cover. The soil map was classified into two classes based on the ratings for the soil texture [2] [20].

Topographic slope (T): This describes the ability of pollutants to infiltrate into the vadose zone and to reach the aquifer [2]. The slope index was derived from the DEM to find the ratings for recharge; based on Table 1 , the topographic slope map was sub-divided into three classes.

Impact vadose zone (I): The impact on the vadose zone was examined by interpreting geological maps of the study area [24]. The aquifer media was classified as fractured basalt and limestone.

\subsection{Modified DRASTIC Index}

Land use is an important factor that must be included in groundwater vulnerability maps because different types of land use strongly affect on groundwater quality through water infiltration. Therefore mismanagement land (misused fertilizers, pesticides, herbicides, amounts of water) may lead to the deterioration of water quality. In general, the land-use factor describes the existing activities in the area that may affect groundwater quality [14]. 
In this study, land use was determined by using GeoEye-1 satellite imagery. Three different land-use classes were defined: irrigated field crops, built-up areas and uncultivated areas.

The areas were manually digitized from the GeoEye- 1 sensor and stored in the local coordinate system of Jordan (JTM). The equation of the modified DRASTIC index is shown in Equation (3):

$$
\text { Modified DRASTIC }=\text { DRASTIC index }+ \text { land }- \text { use index }
$$

\section{Results and Discussion}

\subsection{Mapping the DRASTIC Index}

All output maps from the steps described above were saved in raster format. In order to retrieve the final vulnerability map, the images were processed in the output maps (vulnerability factors) with their Arc View by multiplying the raster values of each of the corresponding vulnerability weighting coefficients.

The final vulnerability map for the NE showed values between 1 and 100 as illustrated in Figure 2. They were separated into vulnerability classes of extremely low, low, moderate, high, and extremely high vulnerability by dividing the value range into five equal classes according to the standard deviation (SD). Table 3 shows the final groundwater vulnerability classes (DRASTIC index).

\subsection{Modified DRASTIC Index}

The land-use map was subdivided into two classes (Figure 3). A relationship could be seen in the overlay between land use and a groundwater vulnerability zone. It was observed that almost of farms and urbanization areas were located inside high vulnerability zone which covered $64 \mathrm{~km}^{2}$ of total area with a possible source of contamination, while less than $5 \mathrm{~km}^{2}$ of farms and urbanization were located in low vulnerability zone with no possible source of contamination. The modified vulnerability map showed values between 1 and 100 (Figure 4).

These values were also separated into vulnerability classes of extremely low, low, moderate, high, and extremely high vulnerability by dividing the value range into five equal classes according to the standard deviation (SD). Table 4 shows modified groundwater vulnerability classes (modified DRASTIC index).

The degrees of groundwater vulnerability have changed after add land use layer. These values changed from variation in the area between bare soil (unused), agriculture and urbanization. Most of the influence on the quality of groundwater in urban and agricultural areas is resulted intensive use of fertilizer, while as for bare soil areas; there is no impact on values of groundwater vulnerability.

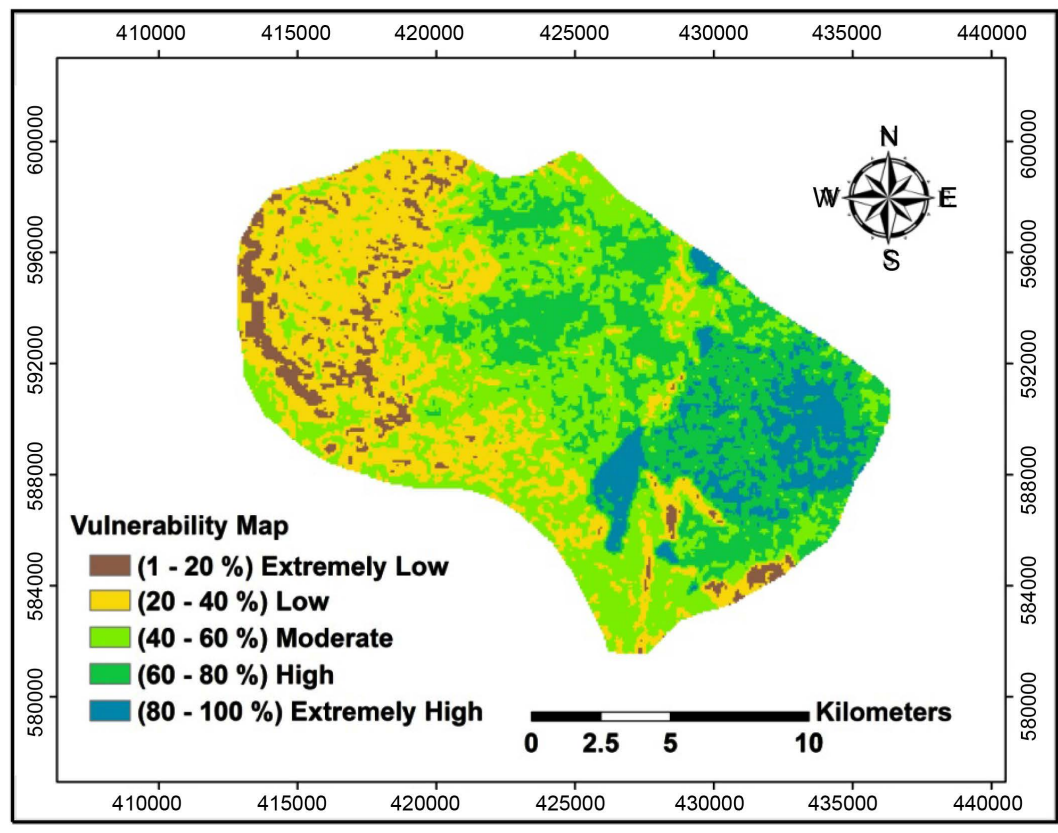

Figure 2. Vulnerability map (DRASTIC index map). 


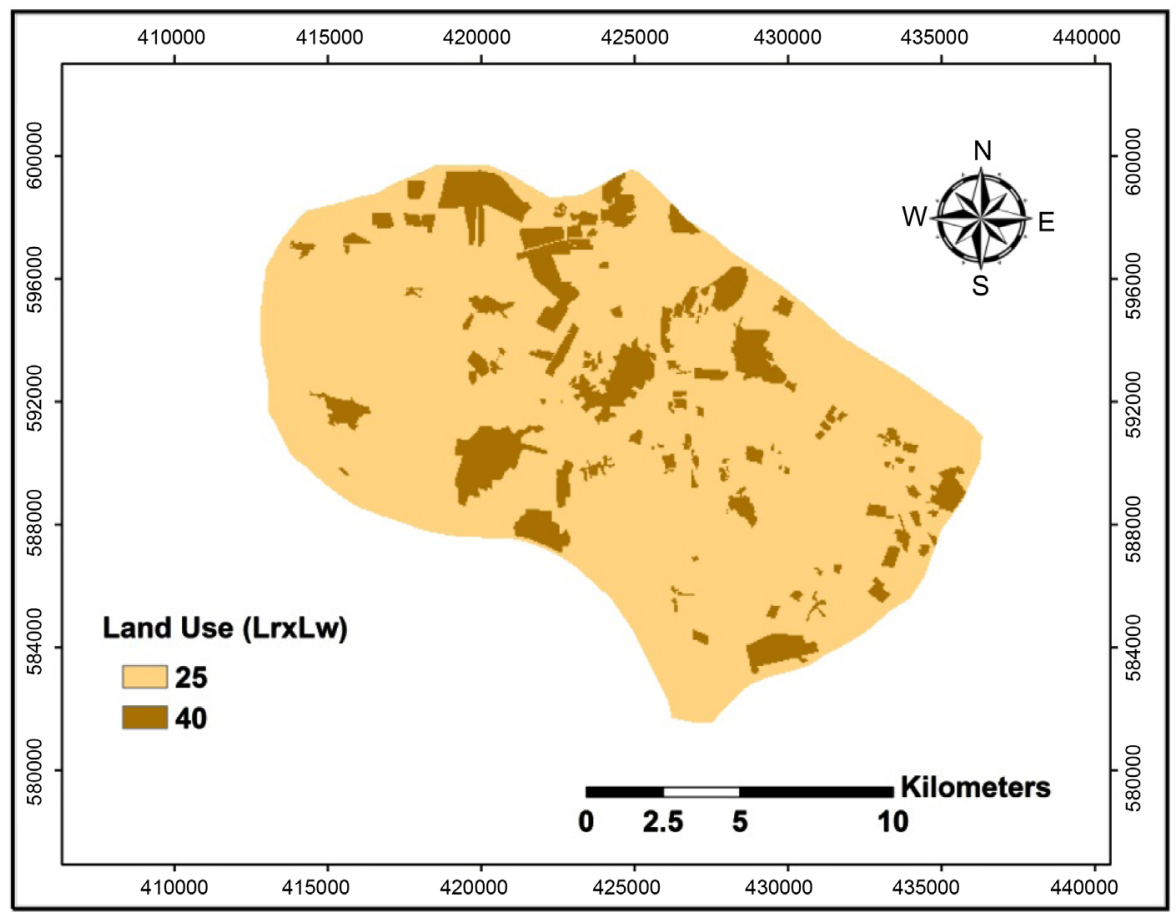

Figure 3. Land use rating and weighting (LrLw).

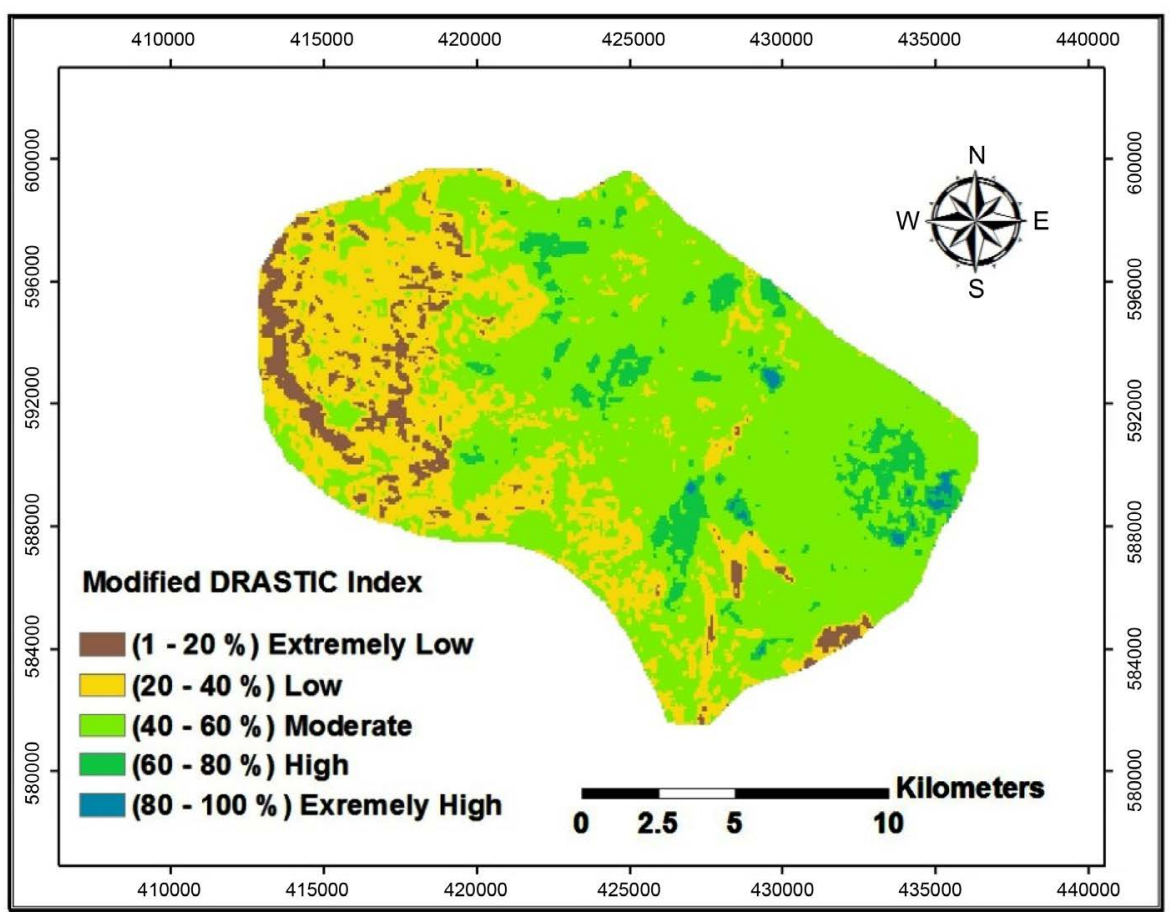

Figure 4. Modified DRASTIC index map.

\subsection{Validation of Modified DRASTIC and SAR}

In order to examine the relationship between groundwater vulnerability and SAR concentrations, the locations of wells were assigned by using GPS, and water samples from each well were analyzed in the lab. The samples were distributed in the study area to measure SAR concentration, in order to match between wells sites, SAR 
Table 3. DRASTIC index for the study area.

\begin{tabular}{cccc}
\hline Class & Range & Area $\mathbf{k m}^{\mathbf{2}}$ & \% of the total area \\
\hline Extremely Low & $1-20$ & 12.7 & 4.9 \\
Low & $20-40$ & 73.1 & 28.6 \\
Moderate & $40-60$ & 87 & 34 \\
High & $60-80$ & 64 & 7.5 \\
Extremely High & $80-100$ & 19.2 & $100 \%$ \\
Total & - & 256 & \\
\hline
\end{tabular}

Table 4. The modified DRASTIC index for the study area.

\begin{tabular}{cccc}
\hline Class & Range & Area $\mathbf{~ k m}^{\mathbf{2}}$ & \% of the total area \\
\hline Extremely Low & $1-20$ & 13 & 5 \\
Low & $20-40$ & 72.5 & 28.3 \\
Moderate & $40-60$ & 153.5 & 60 \\
High & $60-80$ & 16 & 6.3 \\
Extremely High & $80-100$ & 1 & 0.5 \\
Total & - & 256 & $100 \%$ \\
\hline
\end{tabular}

concentrations and modified DRASTIC index to predict the critical situation in the study area. The highest SAR concentration in groundwater in some wells was $18 \mathrm{meq} / \mathrm{l}$. The suitable SAR concentration for irrigation in agriculture is less than 3, according to FAO recommendations for irrigation water quality. However, if the SAR concentration is higher than $9 \mathrm{meq} / \mathrm{l}$ in groundwater, this indicates contamination due to human activities. Thus, this led to a degradation of the soil quality, where it was concluded that the area has a high SAR concentration in the soil that resulted from the mismanagement of irrigation in agricultural areas and the misuse of fertilizers.

The highest SAR concentration in soil samples was at 14 - 20 meq/l and the good parameters (no problem) for the soil quality were less than 4 meq/l, according to Alberta 2010 [25]. The SAR concentration was measured in March 2013. The analysis indicated that the area has a high SAR concentration, which can be correlated to a modified DRASTIC out-put. It was found that SAR concentrations in wells that exist inside the low vulnerability zone vary between 9 and 18. The average concentration of the sodium ratio (SAR) in these wells was about 13. Figure 5 shows the spatial distribution of SAR within the groundwater vulnerability zones.

\section{Conclusions}

Mapping modified of groundwater vulnerability can be improved to be more effective through standardization and calibration of the points values based on the outcomes of relationship that appear for each parameter in the DRASTIC, e.g. relationship of hydrological aquifers with quality of water.

In this case study in NE Jordan, the area was divided into five vulnerability classes (extremely low, low, moderate, high, and extremely high vulnerability) in accordance with its environmental and groundwater settings and standard deviation. It is concluded that about 34\% of the area was considered to be of moderate vulnerability, but increased to $60 \%$ in the modified index-while the high vulnerability was $25 \%$ of the total area and decreased to $6.3 \%$ in the modified index. Therefore, urgent pollution prevention measures should be taken for every kind of relevant activity within the whole basin that shows high values of SAR which reflect the quality of groundwater if located near most farms; it was also observed that the highest SAR values were measured in high to extremely high vulnerability zones.

SAR concentrations in six wells inside the moderate vulnerability zone were much higher than those in the low vulnerability zone. Overlaying between SAR concentrations and modified DRASTIC Index shows that the SAR values located in farms that used fertilizers, Pesticides, so there is a significant relationship between the 


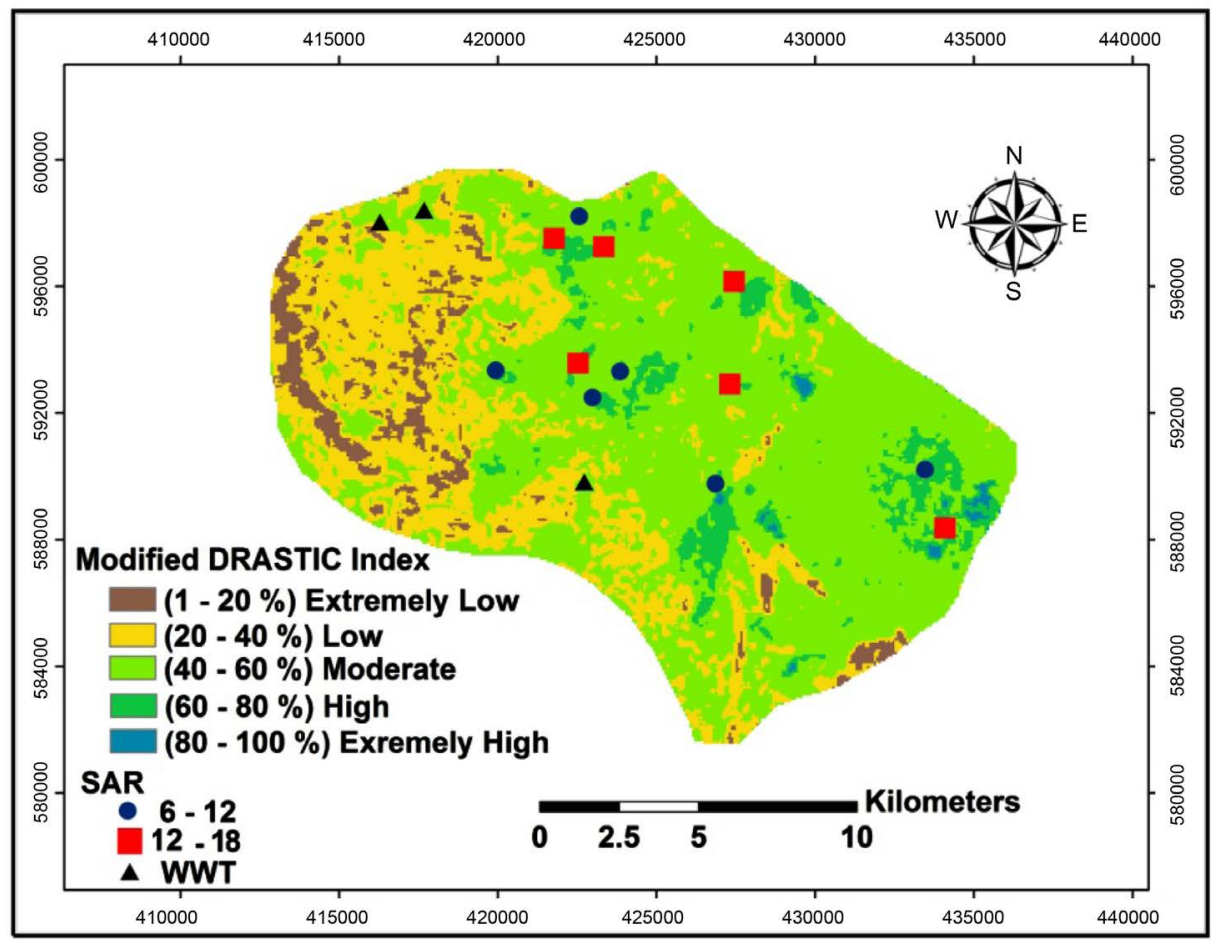

Figure 5. Spatial distribution of SAR within the groundwater vulnerability zones.

SAR values of irrigation water and the extent to which sodium is absorbed by the soils. The continued use of water with high SAR values leads to a breakdown in the physical structure of the soil, because large sodium ions get between particles of soil and clay. Separation of the clay particles from the soil occurs, which results in dispersion, and this leads to reduced soil permeability, followed by a range of further problems in the soil.

Generally, the northern part of the study area has extremely and high vulnerability degree, while the eastern and central parts of study area have moderate, low and extremely low vulnerability degree. As a preliminary solution for pollution sources and this risk, farmers should stop wrong practices of farming and should follow safer methods for agriculture, irrigation, as well as the control of groundwater quality used to irrigate farms.

\section{References}

[1] Murray, K.S. and Rogers, D.T. (1999) Groundwater Vulnerability, Brownfield Redevelopment and Land Use Planning. Journal of Environmental Planning and Management, 42, 801-810. http://dx.doi.org/10.1080/09640569910830

[2] Aller, L., Bennett, T., Lehr, J.H., Petty, R.J. and Hackett, G. (1987) DRASTIC: A Standardized System for Evaluating Ground Water Pollution Potential Using Hydrogeologic Settings. US Environmental Protection Agency, Washington DC, 622.

[3] Foster, S. (1987) Fundamental Concept in Aquifer Vulnerability, Pollution Risk and Protection Strategy. Vulnerability of Soil and Groundwater to Pollutants, TNO Committee on Hydrogeological Research, Proceedings and Information, 38.

[4] Civita, M. (1994) Contamination Vulnerability Mapping of the Aquifer: Theory and Practice. Quaderni di Tecniche di Protezione Ambientale, Pitagora.

[5] Vias, J.M., Andreo, B., Perles, M.J., Carrasco, F., Vadillo, I. and Jiménez, P. (2006) Proposed Method for Groundwater Vulnerability Mapping in Carbonate (Karstic) Aquifers: The COP Method. Hydrogeology Journal, 14, 912-925. http://dx.doi.org/10.1007/s10040-006-0023-6

[6] Doerfliger, N., Jeannin, P.Y. and Zwahlen, F. (1999) Water Vulnerability Assessment in Karst Environments: A New Method of Defining Protection Areas Using a Multi-Attribute Approach and GIS Tools (EPIK Method). Environmental Geology, 39, 165-176. http://dx.doi.org/10.1007/s002540050446

[7] Goldscheider, N., Klute, M., Sturm, S. and Hötzl, H. (2000) The PI Method-A GIS-Based Approach to Mapping Groundwater Vulnerability with Special Consideration of Karst Aquifers. Zeitschrift für Angewandte Geologie, 46, 
157-166.

[8] Merchant, J.W. (1994) GIS-Based Groundwater Pollution Hazard Assessment: A Critical Review of the DRASTIC Model. Photogrammetric Engineering and Remote Sensing, 60, 1117-1128.

[9] USEPA United State Environmental Protection Agencies (1974) Quality Criteria for Water. Trtain, R.C., Ed., Casste House, UK.

[10] Evans, B.M. and Myers, W.L. (1990) A GIS-Based Approach to Evaluating Regional Groundwater Pollution Potential with DRASTIC. Journal of Soil and Water Conservation, 45, 242-245.

[11] Rosen, L.A. (1994) Study of the DRASTIC Methodology with Emphasis on Swedish Conditions. Groundwater, 32, 278-285. http://dx.doi.org/10.1111/j.1745-6584.1994.tb00642.x

[12] Vrba, J. and Zaporozec, A., Eds. (1994) Guidebook on Mapping Groundwater Vulnerability. IAH International Contributions to Hydrogeology, 16, 131.

[13] Al-Adamat, R.A., Foster, I.D. and Baban, S.M. (2003) Groundwater Vulnerability and Risk Mapping for the Basaltic Aquifer of the Azraq Basin of Jordan Using GIS, Remote Sensing and DRASTIC. Applied Geography, 23, 303-324. http://dx.doi.org/10.1016/j.apgeog.2003.08.007

[14] Ibrahim, M. (2014) The Use of Geoinformatics in Investigating the Impact of Agricultural Activities between 1990 and 2010 on Land Degradation in NE of Jordan. PhD Dissertation, Faculty of Environmental and Natural Sciences, Freiburg University, Freiburg im Breisgau.

[15] Salameh, E. (1996) Water Quality Degradation in Jordan. Friedrich Ebert Stiftung and Royal Society for the Conservation of Nature, Amman, Jordan, 178.

[16] El-Naser, H. (1991) Groundwater of the Deep Aquifer System in NW-Jordan: Hydrogeological and Hydrogeochemical Quasi 3-D Modeling. PhD Thesis, University of Würzburg, Würzburg.

[17] Rimawi, O., El-Naqa, A. and Salameh, E. (1992) Hydrochemical Characteristics of Groundwater Resources in Northeastern Part of the Jordan Valley/Jordan. Dirasat, 19, 87-117.

[18] Piscopo, G. (2001) Groundwater Vulnerability Map, Explanatory Notes, Castlereagh Catchment. NSW Department of Land and Water Conservation, Australia.

[19] Secunda, S., Collin, M. and Melloul, A.J. (1998) Groundwater Vulnerability Assessment Using a Composite Model Combining DRASTIC with Extensive Agricultural Land Use in Israel's Sharon Region. Journal of Environmental Management, 54, 39-57. http://dx.doi.org/10.1006/jema.1998.0221

[20] Knox, R.C., Sabatini, D.A. and Canter, L.W. (1993) Subsurface Transport and Fate Processes. USA.

[21] WAJ (Water Authority of Jordan) (2004) Internal Files for Groundwater Basins in Jordan.

[22] MOA (Ministry of Agriculture) (1993) National Soil Map and Land Use Project. The Soils of Jordan. Hunting Technical Services Ltd, in association with Soil Survey and Land, Research Center, 2, 1.

[23] USDA (United State Department of Agriculture) (1994) Permeability Key.

[24] Ibrahim, M. (2010) Environmental Assessment of Land Use Changes Using Remote Sensing and GIS Techniques in Irbid Area. Master Thesis unpublished, Al al-Bayt University, Al Mafraq.

[25] Alberta, E. (2010) Alberta Tier 1. Soil and Groundwater Remediation Guidelines. Government of Alberta. http://environment.gov.ab.ca/info/library/7751.pdf 